\title{
Modal Inter-Comparisons between North Atlantic Accumulated Cyclone Energy and the Atlantic Multi-Decadal Oscillation, and the Pathology of the 2013 Hurricane Season
}

\author{
Tingzhuang Yan*, Shaowu Bao, Leonard J. Pietrafesa, Paul T. Gayes \\ School of Coastal \& Marine Systems Science, Coastal Carolina University, Conway, USA \\ Email: ${ }^{*}$ tyan@coastal.edu
}

Received 26 December 2013; revised 1 February 2014; accepted 12 February 2014

Copyright (C) 2014 by authors and Scientific Research Publishing Inc.

This work is licensed under the Creative Commons Attribution International License (CC BY). http://creativecommons.org/licenses/by/4.0/

(c) (i) Open Access

\begin{abstract}
It is a community wide belief that the Atlantic Multi-decadal Oscillation (AMO) and the Accumulated Cyclone Energy (ACE) are strongly positively correlated and in lock-step for the characterization of a tropical cyclone (TC) - hurricane season; including how many named TCs will form and how many will become hurricanes and major hurricanes [1]-[4]. In this paper, we decompose the AMO and ACE time series into their internal modes of variability using the Hilbert-Huang Transform [5] and the Ensemble Empirical Modal Decomposition (EEMD) [6], and look into the relationships that exist between the individual corresponding modes of the AMO and the ACE. We then evaluate the degrees of frequency domain correlations between the internal modes of variability of the AMO and the ACE across the entire record length time series. The 2013 North Atlantic Hurricane Season, which had been predicted to be "above normal", with an ACE estimated to be between 122 and 138 by the National Oceanic \& Atmospheric Administration (NOAA), turned out to be one of the quietest on record. The actual 2013 observed ACE was only 33 (unit: $10^{4} \mathrm{kn}^{2}$ ) or $29 \%$ of the 65 year (1948-2012) average of 103 (with a median of 89.5) and is the $5^{\text {th }}$ lowest value since 1950. Following the visual correlations between the ACE and the AMO in the past, and assuming past is prologue to the future, the "above normal" forecast of the ACE led to a tropical cyclone community wide forecast of a highly active 2013 hurricane season. So why the busted 2013 forecast? This study will address the possible reasons.
\end{abstract}

\section{Keywords}

North Atlantic Hurricanes Season, ACE, AMO, EEMD, IMF, Mode

\footnotetext{
${ }^{*}$ Corresponding author.
}

How to cite this paper: Yan, T.Z., et al. (2014) Modal Inter-Comparisons between North Atlantic Accumulated Cyclone Energy and the Atlantic Multi-Decadal Oscillation, and the Pathology of the 2013 Hurricane Season. Natural Science, 6, 597-604. http://dx.doi.org/10.4236/ns.2014.68059 


\section{Introduction}

The ACE is a measure used by NOAA to express the wind energy of individual tropical cyclones (TCs) summed over an entire tropical cyclone season in the North Atlantic Ocean Basin (NAOB). It is defined as the sum of the squares of the maximum sustained surface wind speed times $10^{4}\left(\mathrm{knots}^{2}\right)$ measured every six hours for all named systems while they are of tropical storm strength [7]. The ACE of a season takes into account the number, strength, and duration of all the tropical storms in the season. The reason for the $10^{4}$ coefficient is to make the additive numbers more numerically manageable.

The Atlantic Multi-decadal Oscillation (AMO) represents a cycle in the large-scale atmospheric flow and ocean currents in the North Atlantic Ocean that combine to alternately increase and decrease Atlantic sea surface temperatures (SSTs). It is defined as mean SST between $75^{\circ} \mathrm{W}$ and $7.5^{\circ} \mathrm{W}$ and south of $60^{\circ} \mathrm{N}$ to the Equator. The AMO has previously been identified as a coherent pattern of variability in basin-wide North Atlantic SSTs with a cycle of roughly 70 years [8] and is believed to strongly influence the incidence of intense hurricanes [9] [10]. An intense hurricane count year, associated with the warm phase of the AMO [11] is characterized by an ACE to be more than double the count during cool phase years of the AMO. The last phase change, which occurred in 1995, was accompanied by a sudden increase in Atlantic storms, and since then the AMO has been in its warm phase, nearly two decades. However, there is no demonstrated predictability for when the AMO phase will switch in any deterministic sense because there had been too few samples for conventional statistical approaches.

In Figure 1, we present the relationship between the ACE and the SST across the entire Atlantic Ocean Basin. Since the AMO is basically an index of North Atlantic SST, this figure shows clearly that the ACE has a positive correlation with SST across the majority of the North Atlantic Ocean. Figure 1 also implies that the spatial distribution of anomalous SST in NAOB plays a crucial role in tropical cyclone formation and development [12].

In Figure 2, the spatially summed SSTs for the NAOB (red line), are turned into an index of the unsmoothed version of the AMO (1856-2013). We present the unsmoothed version so as to retain the time series index trend. The unsmoothed data were obtained from NCDC. Offhand, it is difficult to visually and definitively determine a 70-year cycle in the AMO. Rather there appears to be a variety of modes of variability superimposed on one the other, all riding what appears to be an upward trend from end to end in the time series.

NOAA's forecasted ACE for the 2013 hurricane season was variously between 122 and 138, well above the climatology of 103 over the period 1948-2012, and thus the TC 2013 season was categorized to be an abovenormal season type. However the observed ACE during the 2013 hurricane season was extremely low (33 $\times 10^{4}$ $\mathrm{kn}^{2}$ ) with only 13 named TCs with only 2 having reached hurricane category. The NOAA Official ACE forecast, based on Bell et al., 2000 was calling for an above normal hurricane season and as such the TC outlook was for an above average season in kind. The 65-year (1948-2012) long-term mean ACE is $103\left(10^{4} \mathrm{kn}^{2}\right)$ and the median ACE value is $89.5\left(10^{4} \mathrm{kn}^{2}\right)$. In the text to follow we will drop the $10^{4}$ and refer to the ACE in modified units which infer they are $10,000^{\text {th }}$ of their actual energy values.

Using AMO indices as a predictor combined with the El Nino Southern Oscillation (ENSO), the Atlantic Meridional Mode, and the Tropical North Atlantic Index, the hindcasting skill of ACE significantly exceeds the climatology (Figure 3).

Using the observed ACE through each of the retrospective year-seasons (1950-2012) combined with ENSO and SST anomalies in selected Atlantic Ocean domains, a hindcasting of the number of tropical storms, hurricanes and major hurricanes are shown in Figures 4(a)-(c). The TC activity for each year was predicted by removing the actual activity for that year from the assessment and subsequently predicted completely independently.

Obviously the past predictions of numbers of named storms, hurricanes and major hurricanes, have either been spot on or at most been off by a storm or two. So the retrospective study was highly successful. But what has gone so very wrong in 2013? Notice that the difference between the 2013 forecast and the retrospective study is that actual observed ACE was used for hindcasting while the forecasted ACE was used for the 2013 forecast. The inaccurate ACE prediction seems to have significantly downgraded the model to a considerable degree and therefore seems to have caused the busted prediction of 2013. Since the AMO is one of the key factors for the community-wide ACE forecasts, and since it is also one key factor for the above retrospective study, a question raised is, is the AMO one of or the key factors that caused the failure of the 2013 TC seasonal outlook? 


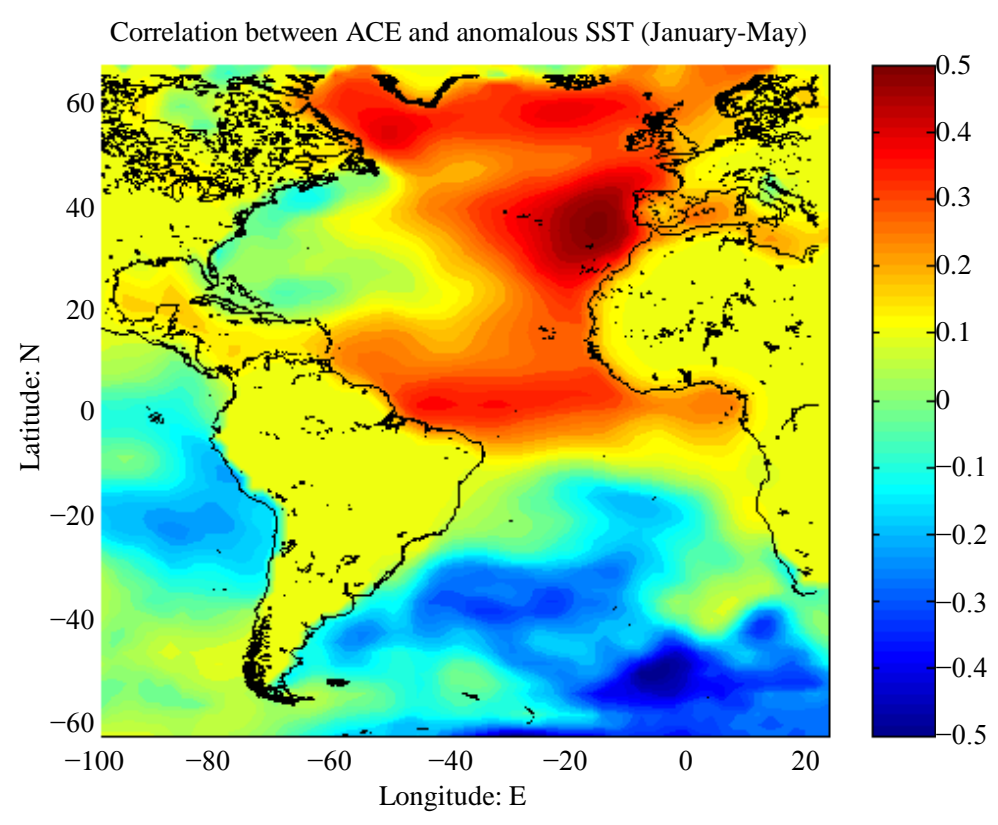

Figure 1. The AMO (expressed as anomalous SSTs) during the period January-May, 1950 to 2013, correlated to ACE. The data was obtained from the NOAA Climate Data Center (NCDC) archives.

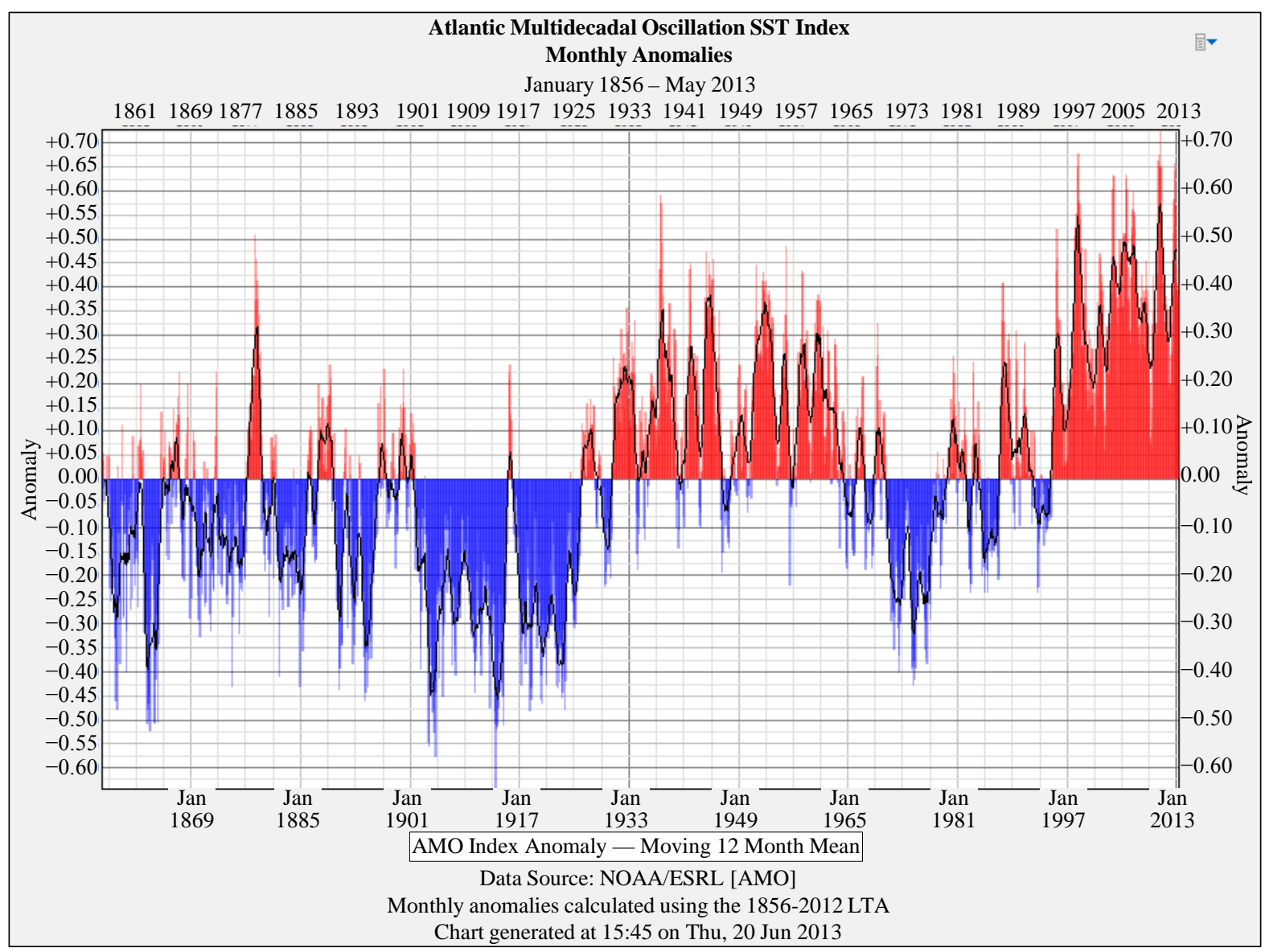

Figure 2. Monthly anomalies of the AMO (Jan. 1856-May 2013). 


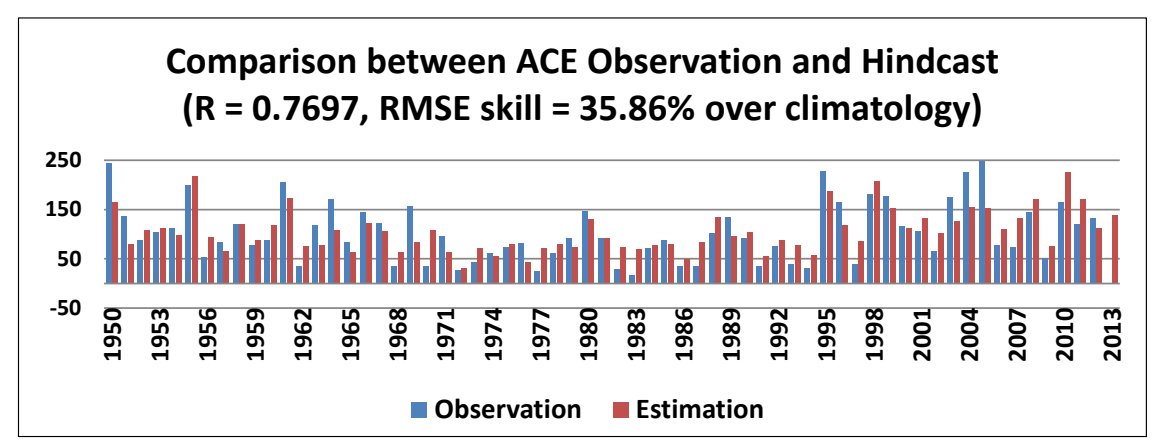

Figure 3. Hindcasting of the ACE using AMO and other climate factors.

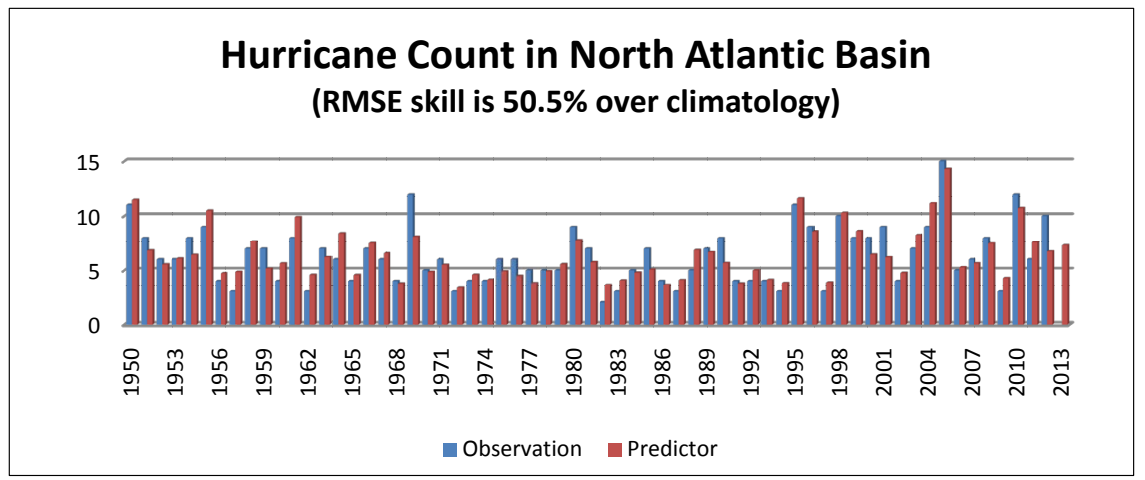

(a)

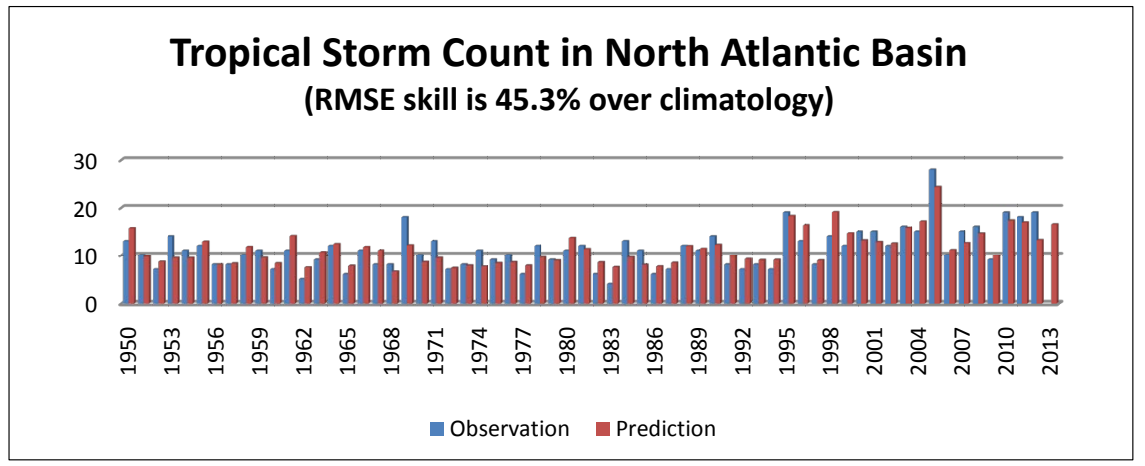

(b)

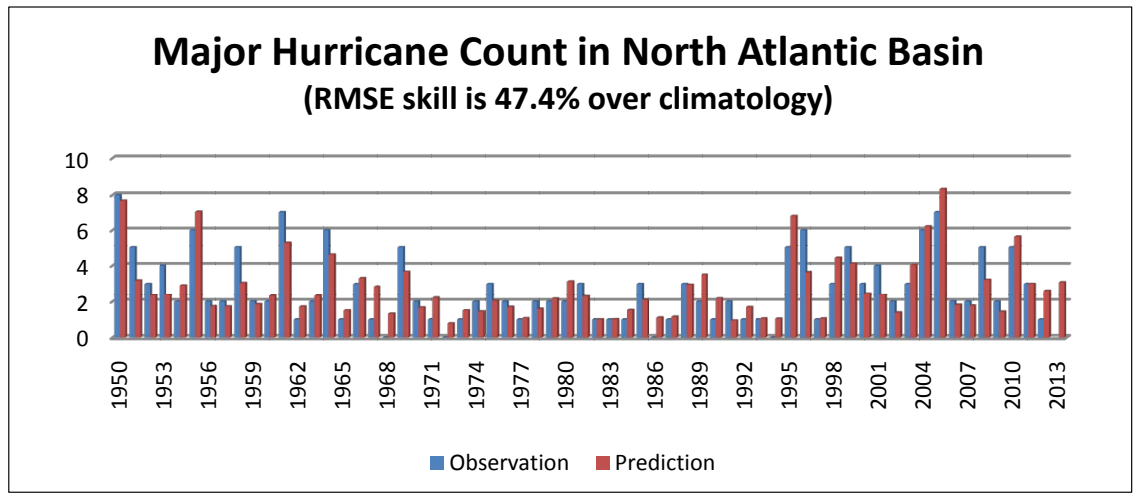

(c)

Figure 4. Hurricane Seasons from 1950 through 2012 with the 2013 forecast also shown for: (a) Named storms; (b) Hurricanes; (c) Major Hurricanes. 


\section{ACE and AMO Data Analyses}

Estimates of the ACE and of TC activity (not shown) back to 1856 are quite impressive given the tools of the trade prior to World War II (WWII). However, following WWII, the US observational SST and TC observing networks improved greatly given the ambitious efforts of the US Air Force, Navy and Army. US Department of Defense agencies collectively began a more thorough documentation of TC activity in the Atlantic and Pacific Ocean Basin beginning in 1948. Thus we will focus our analysis based on statistics of NOAA's ACE record over the past six decades (1948-2013). In Figure 5, the normalized ACE by year is plotted against its AMO analogue and reveals a strong positive correlation. The correlation varies rather dramatically between cool and warm AMO phases. For example, an average of $139 \mathrm{kn}^{2} /$ year has been observed during the current warm phase (1995-2012) of the AMO, while only $65 \mathrm{kn}^{2} /$ year was observed during the last AMO cool phase (1970-1994). As shown in Figure 5, there have been huge inter-annual to multi-year to decadal swings in ACE values. The up and down swings of the ACE and the AMO are occasionally in-phase and occasionally out-of-phase. The long term variability of both ACE and AMO also display obvious downward anomalies from 1948 to the 1970s, and then upward swings into the early 2000s. The 1970s and 1980s have been referred to as the inactive hurricane era.

We see positive peaks of the ACE in 1950, 1955, 1961, 1995, 2004 and 2005 with highest values in 1950 and 2005. The AMO was quite high in 1955, 1961, 1995, 2004 and 2005, but during the anomalously high ACE year of 1950, the AMO was slightly negative. Visually, even if the AMO were the principal predictor for ACE, given the broad suite of climate factors likely influencing TC production or the lack thereof, it would occasionally have failed.

As we are principally interested in the 2013 busted forecast we will assess the years during which there were 15 relatively lower values, equal or less than -0.5 of the ACE. These are values of ACE that were not just negative but even less than -0.5 . They occurred in 1962, 1965, 1968, 1970, 1972, 1977, 1982, 1983, 1986, 1987, 1991, 1993, 1994, 1997 and 2013. Relatively low or more emphatically, lower AMO anomalies were achieved 21 times overall, 1965, 1968, 1971, 1972, 1973, 1974, 1975, 1976, 1977, 1978, 1979, 1982, 1984, 1985, 1986, 1989, 1990, 1991, 1992, 1993 and 1994, but only in 9 of the 15 low ACE years; a 60\% hit rate which is not in keeping with a one-to-one relationship between the two. So we are at a quandary. Thus, we now employ the HHT and EEMD to further analyze these time series, especially those ACE years which may have been out of sync with AMO year classes.

From Figure 5, both ACE and AMO separate time series appear visually to be highly non-stationary and nonlinear. In analyses of these data, we need to address the issues of non-stationary (NS) and non-linear (NL) signals in the various data sets. One cannot establish trends through time series of either NS or NL data by subjectively drawing straight lines through the data. Moreover we cannot conduct any sort of running or boxcar averaging as we do not know the inherent time scales of variability that are buried within the suite of data sets. As such we employ an empirical mathematical approach and process all of the time series by employing the HHT which will allow us to conduct an EEMD of our selected time series. We will then be able to properly compute overall trends and temporal rates of change of the overall trends of both time series. It is a methodology which allows for proper treatment of NS and NL data [6]. Neither Fourier analysis nor Wavelet Analysis can properly transform and preserve the content of NS and NL time series. These deficiencies are detailed in the seminal Huang et al. study [5]. Utilizing an HHT we reveal the internal cycles of variability or more formally, the Intrinsic Mode Functions (IMFs), buried within the data sets.

The mode of the lowest frequency IMF is the overall trend of the time series. There are 6 internal or rather intrinsic modes of variability (IMFs). The $1^{\text {st }}$ modes (Modes 1 ) have a $3-4$ year period, the $2^{\text {nd }}$ modes are $6-7$ years, Modes 3 are 20 - 22 years, IMFs 4 are $\sim 40$ years and IMFs 5 are $\sim 65$ years. Modes 6, the overall trends, are such that the ACE shows a downward trend from the onsets of the time series to 2000, and flatten thereafter with an ever so slight upward trend, while the AMO demonstrates a downward trend from the beginning, a bottoming out in the 1970s and rises since late 1970s.

Visually, ACE IMF modes are in sync with ACE IMF modes at all different frequency domains. ACE IMF mode 1 is in and out of sync with AMO IMF mode 1 at a period of 3 - 4 years. A significant fact is that during those AMO misleading years, the AMO and ACE are in opposite phase in this low frequency domain, which means if we use AMO for ACE forecasting in those years, a positive AMO value would predict a low ACE, and vice verse. 


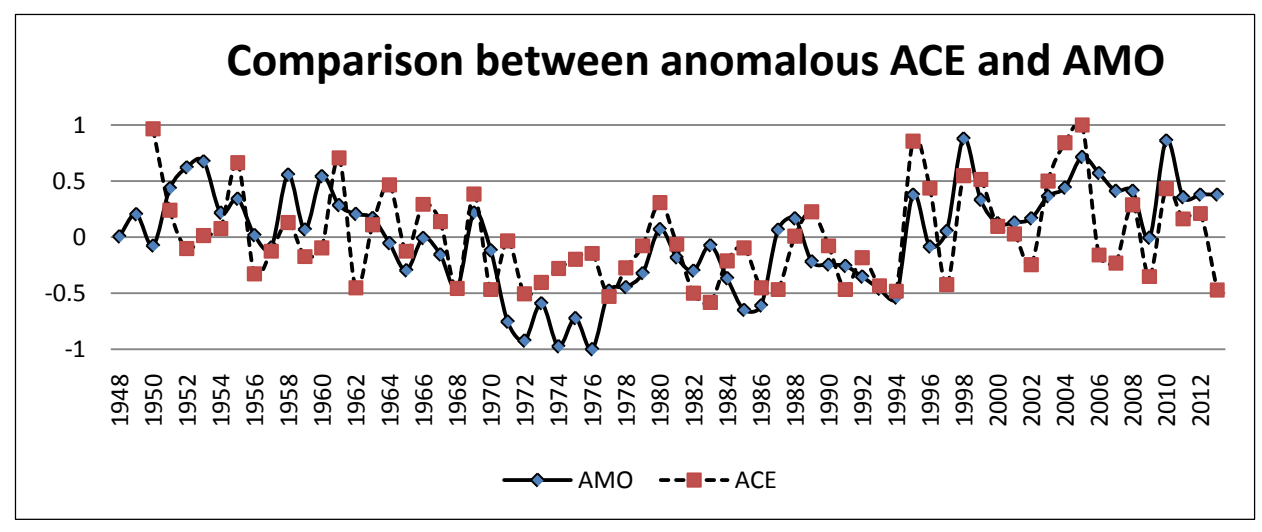

Figure 5. The AMO mean anomaly index (January-July) (dashed line) and ACE anomaly index from 1948 through 2013 (solid line). Data was obtained from NOAA NCDC.

AMO and ACE IMF 2 are in lock-step oscillation. Each has their own oscillation period varying at a period of 6 - 7 years. In this temporal domain, AMO values in 1950 and 1987 are in sync with ACE values, while AMOs in 1962 and 2013 are out of sync and in opposite phase. A notable fact is that the AMO and the ACE in 1950 and 1987 are on upward sides of the curves, while in 1962 and 2013 they are in the downward side of the curves. AMO IMF 3, 4 and ACE IMF 3, 4 are tightly visually correlated at a period of 20 - 22 and 40 years, respectively. During those years however, the ACE and the AMO are actually in sync. In the lower frequency domain, the ACE and AMO oscillate at a period of $\sim 65$ years. It seems that AMO and ACE are not quite as well correlated as IMFs 3 and 4, though the values of ACE and AMO in those frequency domains are in the same phase.

As we stated previously, the AMO of each season was one of the principal factors used for those yearly ACE forecasts. The ACE was then used to forecast the particular hurricane season. Our retrospective hind-casts used actual year-end observations of the ACE and were then compared to actual outcomes through each of the respective year-seasons. However in 2013, the forecasted ACE was based on the observed AMO. If we now revisit the values of the AMO IMFs as shown in Figure 6: AMO IMF 1, which is the dominant mode (with largest magnitude), has the second lowest value in the past 66 year period (only larger than the value in 1994); IMF 2 is positive, IMF 3 and IMF 4 are negative. The ACE IMFs 1 - 4 are all negative and downward; and IMFs 5 and 6 are near zero. The combination of those modes actually yields a negative AMO value for 2013.

Given the values of the AMO and the ACE suggested by the HHT EEMD modal decomposition, the ACE for 2013 was unlikely to have been above normal, even assuming that the dominant mode, IMF 1, would be positive. Moreover, simple straight line extensions of the IMF modes 1 - 6 into the 2103 year would have resulted in an ACE of 65, a well below "normal" season projection for the ACE. From Figure 6, a forecast of an ACE of below or near normal would have resulted in a "below normal" hurricane season; and not an "above normal" season. This would have altered the outlook for the 2013 TC season.

\section{Conclusions}

The AMO is one of the key factors that influence tropical cyclongenesis in the NAOB, though other climatic/ oceanic factors also play important roles. The AMO itself has oscillations at different frequency domains influenced by other climate factors. Mode 1 at high frequency domain is in sync with actual ACE variations.

Low frequency oscillations in the AMO are known to be driven by cyclic variations in large-scale atmospheric flows and ocean currents in the North Atlantic Ocean with multiyear and multi-decadal year periods. However, the factors that control high frequency variability are still unknown. We are cautioned in using the AMO for the ACE forecast as we have seen that the observed AMO value could be very misleading of the ACE forecast without an EEMD analysis. From the above analysis, the following conclusions are reached:

1) The AMO and ACE are generally but not always well correlated or connected;

2) The AMO and ACE exhibit similar periods, i.e., cycles of variability ranging from annual to inter-annual to multi-year to multi-decadal periods;

3) IMF 1 for the AMO is the dominant mode influencing ACE activity for any TC season;

4) IMFs 2, 3, 4 and 6 can additively dominate IMF 1 and have comparable amplitudes; 
EEMD Modes for ACE (solid line) and AMO (dotted line)
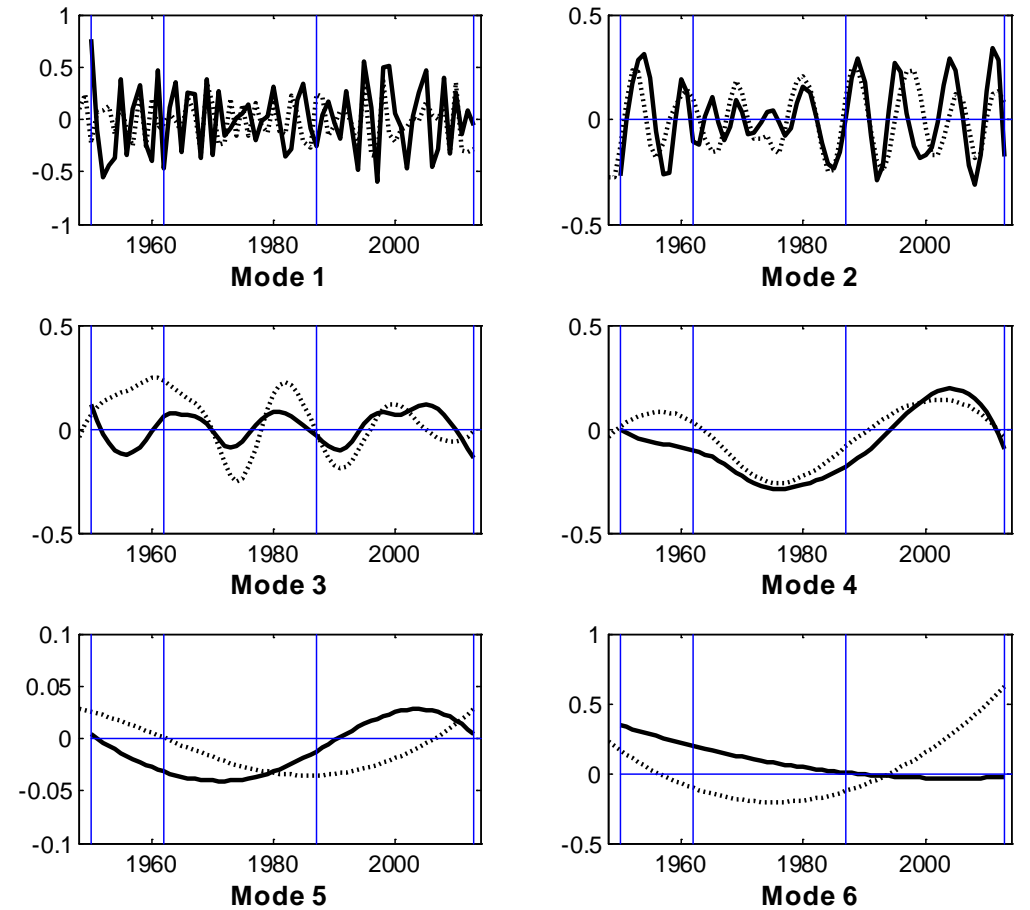

Figure 6. IMFs 1 - 6 for the AMO and ACE time series. (Vertical blue lines represents X-axis locations for the years 1950, 1962, 1987 and 2013).

5) The influence of the AMO on the ACE varies from year to year in tropical cyclogenesis in the NAOB; and

6) Climatic oceanic factors that drive AMO oscillations are not necessarily the same as those controlling the ACE and need to be further investigated.

\section{Acknowledgements}

The School of Coastal \& Marine Systems Science at Coastal Carolina University is thanked for providing support of the Hurricane Genesis \& Outlook (HUGO) project.

\section{References}

[1] Bell, G.D. and Chelliah, M. (2006) Leading Tropical Modes Associated with Interannual and Multi-Decadal Fluctuations in North Atlantic Hurricane Activity. Journal of Climate, 19, 590-612. http://dx.doi.org/10.1175/JCLI3659.1

[2] Goldenberg, S.B., Landsea, C.W., Mestas-Nuñez, A.M. and Gray, W.M. (2001) The Recent Increase in Atlantic Hurricane Activity: Causes and Implications. Science, 293, 474-479. http://dx.doi.org/10.1126/science.1060040

[3] Enfield, D.B. and Cid-Serrano, L. (2010) Secular and Multidecadal Warmings in the North Atlantic and Their Relationships with Major Hurricane Activity. International Journal of Climatology, 30, 174-184.

[4] Yan, T., Pietrafesa, L.J., Dickey, D.A., Gayes, P.T. and Bao, S. (2014) Seasonal Prediction of Land-Falling Hurricanes along Eastern Seaboard of the United States. International Journal of Climatology.

[5] Huang, N.E., Shen, Z., Long, S.R., Wu, M.C., Shih, E.H., Zheng, Q., Tung, C.C. and Liu, H.H. (1998) The Empirical Mode Decomposition and the Hilbert Spectrum for Nonlinear and Non-Stationary Time Series Analysis. Proceedings of the Royal Society A, 454A, 903-995. http://dx.doi.org/10.1098/rspa.1998.0193

[6] Wu, Z. and Huang, N.E. (2007) Ensemble Empirical Mode Decomposition: A Noise Assisted Data Analysis Method. Advances in Adaptive Data Analysis, 1, 1-41.

[7] Bell, G.D., Halpert, M.S., Schnell, R.C., Higgins, R.W., Lawrimore, J., Kousky, V.E., Tinker, R., Thiaw, W., Chelliah, M. and Artusa, A. (2000) Climate Assessment for 1999. Bulletin of the American Meteorological Society, 81, 13281328. http://dx.doi.org/10.1175/1520-0477(2000)081<1328:CAF>2.3.CO;2

[8] Schlesinger, M.E. and Ramankutty, N. (1994) An Oscillation in the Global Climate System of Period 65-70 Years. 
Nature, 367, 723-726. http://dx.doi.org/10.1038/367723a0

[9] Mann, M.E. and Emanuel, K.A. (2006) Atlantic Hurricane Trends Linked to Climate Change. Eos, 87, $233-241$. http://dx.doi.org/10.1029/2006EO240001

[10] Sriver, R.L. and Huber, M. (2006) Low Frequency Variability in Globally Integrated Tropical Cyclone Power Dissipation. Geophysical Research Letters, 33, L11705. http://dx.doi.org/10.1029/2006GL026167

[11] Gray, W.M. (1984) Atlantic Seasonal Hurricane Frequency: Part I: El Niño and 30-mb Quasi-Bienniel Oscillation Influences. Monthly Weather Review, 112, 1649-1668. http://dx.doi.org/10.1175/1520-0493(1984)112<1649:ASHFPI>2.0.CO;2

[12] Yan, T., Pietrafesa, L.J., Dickey, D.A., Bao, S., Huang, N.E. and Wu, Z. (2010) North Atlantic Ocean Basin Tropical Cyclone Activity as Related to Climate Factors for the 2010 Hurricane Season. Advances in Adaptive Data Analysis, 2, 463-508. http://dx.doi.org/10.1142/S1793536910000586 